Abstract AB0211 - Table 1

\begin{tabular}{|c|c|c|c|c|}
\hline \multirow[t]{2}{*}{ Baseline Characteristic } & \multicolumn{3}{|c|}{ Univariate analysis } & \multirow{2}{*}{$\begin{array}{c}\text { Multivariate analysis } \\
\text { OR }(95 \% \mathrm{Cl})\end{array}$} \\
\hline & DAS28<2.6 & No remission & OR $(95 \%$ IC) & \\
\hline Age, mean (SD), years & $55.46(13.21)$ & $48.34(12.38)$ & $7.11(3.26,10.96)^{\star \star}$ & 0.124 \\
\hline Female, $\mathrm{n}(\%)$ & $41(33.3)$ & $82(66.7)$ & ns & 0.173 \\
\hline Current smoking, $\mathrm{n}(\%)$ & $12(21.4 \%)$ & $54478.6)$ & $2,84(1.37-5.89)^{\star \star}$ & $0.37(0.16,0.86)^{*}$ \\
\hline Caffeine, $\mathrm{n}(\%)$ & $33(29,2 \%)$ & $80(70,8)$ & $2.35(1.26-4.39)^{\star \star}$ & 0.092 \\
\hline Functional status $>\ln (\%)$ & $38(29.0 \%)$ & $93(71.0)$ & $3,23(1.65-6.31)^{\star *}$ & $2.39(1.06,5.40)^{\star}$ \\
\hline Extra-articular involv, n (\%) & $7(20,6 \%)$ & $27(79.4)$ & $2,63(1.08-6.43)^{*}$ & 0.107 \\
\hline MTX adverse events, $\mathrm{n}(\%)$ & $20(24,1 \%)$ & $63(75,9)$ & $2.85(1.50-5.40)^{\star *}$ & $0.44(0.20,0.95)^{\star}$ \\
\hline Baseline DAS28PCR, mean (SD) & $3.88(0.56)$ & $4,75(0,76)$ & $-0,87(-1.06,-0.67)^{\star \star}$ & $5.79(2.99,11.20)^{\star \star}$ \\
\hline MTX delay, mean (SD), m & $1.66(3.91)$ & $5,39(18.57)$ & $-3.73(-7.28,-0.18)^{\star}$ & 0.089 \\
\hline
\end{tabular}

Abstract AB0211 - Table 2

\begin{tabular}{|c|c|c|c|c|c|c|}
\hline Smoking history & Edad & ACPA & MTX dose & Remission $(n=67)$ & Low activity $(\mathrm{n}=98)$ & Need for biological $(n=60)$ \\
\hline $\begin{array}{l}\text { Never Smoking ( } n=67), \%(S D) \text {, } \\
\quad \text { diff }(95 \% \mathrm{Cl})\end{array}$ & $\begin{array}{c}53,85(15.23)^{\star} \\
4.58(0.32 \text { to } 8.82)\end{array}$ & $\begin{array}{c}126.03(146.91)^{\star} \\
-3.97(-103.03 \text { to }-4.90)\end{array}$ & $\begin{array}{c}16,86(3.92) \\
n s\end{array}$ & $\begin{array}{c}28(41.8) \\
\text { ns }\end{array}$ & $\begin{array}{c}39(58.2) \\
n s\end{array}$ & $\begin{array}{c}19(28.4) \mathrm{ns} \\
\mathrm{ns}\end{array}$ \\
\hline $\begin{array}{l}\text { Former Smoker }(\mathrm{n}=59), \%(\mathrm{SD}) \text {, } \\
\quad \operatorname{diff}(95 \% \mathrm{Cl})\end{array}$ & $\begin{array}{c}65.97(58.68) \\
n s\end{array}$ & $\begin{array}{c}188.81(159.17) \\
n s\end{array}$ & $\begin{array}{c}15.97(3.34)^{\star} \\
-1.44(-0.29 \text { to }-2.59)\end{array}$ & $\begin{array}{c}27(45.8) \\
n s\end{array}$ & $\begin{array}{c}39(66.1)^{\star} \\
1.67(1.06 \text { to } 2.63)\end{array}$ & $\begin{array}{c}14(23.3) \\
\mathrm{ns}\end{array}$ \\
\hline $\begin{array}{l}\text { Current smoker }(n=56), \%(S D) \text {, } \\
\quad \text { diff }(95 \% \mathrm{Cl})\end{array}$ & $\begin{array}{c}45.34(9.94)^{\star *} \\
-8.11(-2.02 \text { to }-4.12)\end{array}$ & $\begin{array}{c}171.03(166.99) \\
\text { ns }\end{array}$ & $\begin{array}{c}18.08(3.63)^{\star \star} \\
1.63(2.79 \text { to } 0.47)\end{array}$ & $\begin{array}{c}12(21.4)^{\star \star} \\
0.46(.26 \text { to } 0.82)\end{array}$ & $\begin{array}{c}20(35.7)^{\star \star} \\
0.47(0.3 \text { to } 0.75)\end{array}$ & $\begin{array}{c}27(48.2)^{\star \star} \\
2.62(1.36 \text { to } 5.06)\end{array}$ \\
\hline
\end{tabular}

${ }^{*} p<0.05,{ }^{* *} p<0.01$.

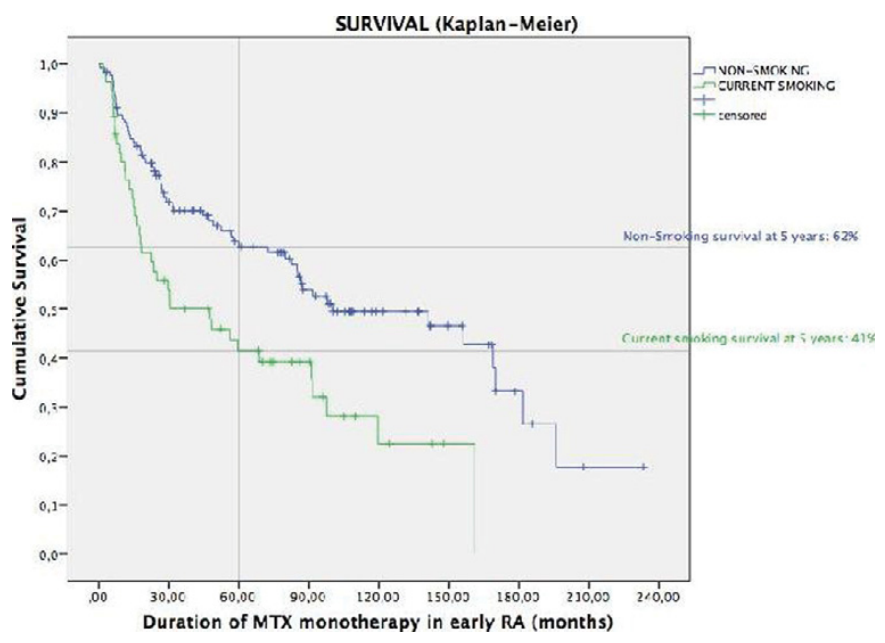

References:

[1] Söderlin, et al. Scandinavian Journal of Rheumatology. 2011;40(4):249-55.

Disclosure of Interest: None declared

DOI: 10.1136/annrheumdis-2017-eular.6739

\section{AB0212 CLINICAL AND SOCIODEMOGRAPHIC CHARACTERISTICS ASSOCIATED WITH RESPONSE TO METHOTREXATE (MTX) IN A COHORT OF PATIENTS WITH RHEUMATOID ARTHRITIS (RA) NAÏVE TO DMARD}

E. Chamizo-Carmona ${ }^{1}$, C. Carrasco Cubero ${ }^{2}$, P.J. Cossio Jimenez ${ }^{1}$, S.M. Rojas Herrera $^{1}$, T.L. Rodriguez Araya ${ }^{1}$, R. Veroz Gonzalez ${ }^{1}$, J.J. Aznar Sanchez ${ }^{1}$.

${ }^{1}$ Rheumatology, Hospital de Merida, Merida; ${ }^{2}$ Rheumatology, CHU Badajoz, Badajoz, Spain

Background: RA treatment involves starting early with a DMARD. MTX achieves good sustained response in $30-40 \%$ of patients (pts). When MTX response is insufficient add other DMARD by achieve RA remission. Different factors may affect the response to MTX

Objectives: To analyze the clinical and demographic characteristics related to response to MTX in RA pts DMARD-naïve

Methods: We enrolled between 2011 and 2015, pts > 18years RA diagnosed (ACR 1987 criteria), treated firs with MTX monotherapy (MTXm). A case-control study (MTXm persistence with CRP-DAS28 $<3.2$ and suspension of MTXm by ineffectiveness or toxicity, respectively) was performed. We collected information that can influence the response to MTXm by medical records review and patient survey. A descriptive and analitical study with SPSS statistics 21 was performed Results: We included 222 pts (70 men and 152 women). The characteristics of cases (123) and controls (99) are shown in the table. The causes of MTXm suspension were remission (7), intolerance/toxicity (19) and inefficiency (79). MTX was discontinued in $40(18.2 \%)$ pts, $28(12.7 \%)$ of them by intolerance/toxicity. Of $123(55.4 \%)$ responders, $71(32.0 \%)$ were CRP-DAS28<2.6. MTXm response was associated with age at onset $\geq 60$ years $(x 218.47, p<0.01$, OR 3.67), rheumatoid factor (RF) $<100 \mathrm{IU}(\times 2$ 10.92, $\mathrm{p}<0.01, \mathrm{OR} 3.16)$ and current smoking ( $x 212.71, p<0.01, \mathrm{OR} 2.95)$. Tobacco was associated with $\mathrm{RF}+(x 28.9$ $p<0.01$ OR $2.59(1.37 ; 4.89)$ and ACPA+ $(x 24.49 p<0.05$ OR $1.88(1.04,3.38)$. We found no association with gender, education, job, coffee, tea or alcoho drinks, comorbidities, cardiovascular risk, possitivity ACPA or FR, RA presentation, treatment delay, or corticosteroid use. We found no correlation between age of
RA-onset and RF or ACPA levels and MTXm duration. MTXm persistence at 5 years was $59 \%$ pts and their median survival was 93 months (77.14 to 108.8). We only found significant differences in favor of non-smokers and $\mathrm{RF}<100$

Table 1. Clinical and sociodemographics characterisitics of RA patients

\begin{tabular}{|c|c|c|c|}
\hline Characteristics & $\begin{array}{c}\text { Responders } \\
\mathrm{n}=125\end{array}$ & $\begin{array}{c}\text { Nonresponders } \\
\mathrm{n}=99\end{array}$ & Statistic Significancy \\
\hline Age at onset (y) (mean, SD) & $53.48(13.0)$ & $46.65(11.5)$ & $t=4.08 p=00006$ \\
\hline Female $\mathrm{n}(\%)$ & $80(65.0)$ & $72(72.7)$ & ns \\
\hline Current Smokers n (\%) & $23(18.7)$ & $40(40.4)$ & $\begin{array}{l}x^{2} 12.7(p<0,01) \\
\text { OR } 2.95(1.6,5.4)\end{array}$ \\
\hline Alcohol consumers $\mathrm{n}(\%)$ & $35(28.5)$ & $28(28.3)$ & ns \\
\hline Comorbidity n (\%) & $92(74.8)$ & $61(61.6)$ & $\begin{array}{l}\chi^{2} 4.45(p<0.05) \\
\text { OR } 1.21(1.0,1.5)\end{array}$ \\
\hline $\mathrm{CV}$ risk factors $\mathrm{n}(\%)$ & $92(74.8)$ & $81(81.8)$ & ns \\
\hline Polyarticular onset of AR $n(\%)$ & $61(49.6)$ & $61(61.6)$ & ns \\
\hline Extraarticular involvement $\mathrm{n}(\%)$ & $17(13.8)$ & $21(21.2)$ & ns \\
\hline Possitive RF n (\%) & $89(72.4)$ & 79 (79.8) & ns \\
\hline Possitive ACPA n (\%) & $70(60.3)$ & $64(68.1)$ & ns \\
\hline Duration of RA (m) (mean (SD) & $96.1(63.1)$ & $96,0(73.9)$ & ns \\
\hline MTX toxicity n (\%) & $47(38.2)$ & $59(59.6)$ & $\begin{array}{c}\chi^{2} 10.0(p<0.01) \\
\text { OR } 2.38(1.4,4.1))\end{array}$ \\
\hline MTX dose $(\mathrm{mg})$ (mean, SD) & $15.6(0.32)$ & $17.8(0.37)$ & $\mathrm{t}=-4.52 \mathrm{p}=00001$ \\
\hline
\end{tabular}

Conclusions: The initial treatment of RA with MTX is an effective and safe option, with a high drug survival. MTX response was not associated with antibody positivity (RF or ACPA), but it was significantly better in non-smokers patients and $\mathrm{RF}<100$. Smoking cessation could significantly improve the response to MTX of RA patients

References:

[1] Saevarsdottir S, et al. Arthritis Rheum 2011;63:26-36.

[2] V. K. Ranganath et al. Rheumatology 2013;52:1809-1817.

Disclosure of Interest: None declared

DOI: 10.1136/annrheumdis-2017-eular.1109

\section{AB0213 HIGH POWER DOPPLER SIGNALS SEEMS MORE IMPORTANT THAN SYNOVITIS SCORES IN ESTABLISHED RHEUMATOID ARTHRITIS}

E.D. Keskin ${ }^{1}$, F.G. Yurdakul ${ }^{2}$, H. Bodur ${ }^{2}$, A. Akıncı Tan ${ }^{3}$, L. Özçakar ${ }^{3} .{ }^{1}$ Physical Medicine and Rehabilitation, Kırıkkale University Faculty of Medicine, Kırıkkale; ${ }^{2}$ Physical Medicine and Rehabilitation, Ankara Numune Training and Research Hospital; ${ }^{3}$ Physical Medicine and Rehabilitation, Hacettepe University Faculty of Medicine, Ankara, Turkey

Background: Rheumatoid arthritis (RA) is a chronic systemic inflammatory disease characterized by synovial inflammation, potential cartilage and bone damages. Evaluation with ultrasound (US) has come into prominence due to conventional radiography is relatively insensitive on soft tissue inflammatory changes and early bone erosions $(1,2)$.

Objectives: The value of US has been shown in early arthritis, but is not well known for established RA. The aim of this study is to determine the relation between US signal, disease activity, articular damage and disability in established RA patients.

Methods: Forty-four RA patients (21 women, 23 men) were enrolled to the study. Age and gender, duration of disease, morning stiffness, disease activity score 28 (DAS28), The Rheumatoid Arthritis Articular Damage (RAAD) score, Hand disability Index (HDI), DASH (Disabilities of the Arm, Shoulder and Hand) scale, and grip strength values were recorded. Wrist, I-II- III. metacarpophalangeal and proximal interphalangeal joints of dominant hand were examined by both $\mathrm{B}$ mode US (BMOD) and Power Doppler US (PDUS).

Results: All of the 44 patients were established RA. The median of disease 
duration was $156(48-420)$ months. DAS 28 score was $2.86(0.68-5.70)$ and $54.5 \%$ of the patients were in remission. BMOD synovitis, erosion and PDUS synovitis total scores were $20(6-36) ; 6(0-17) ; 1(0-14)$ respectively. Although US findings were not correlated with DAS 28 and grip strength; there was poor correlation between US findings and DASH, RAAD and disease duration (Table 1). Signs of synovitis indicated with PDUS in $63.3 \%$ of the joints assessed. High-grade PDUS signal (grade 3) was found in $10(22.7 \%)$ of the patients. Duration of morning stiffness, $\mathrm{HDI}$ and DASH scores were worse in the patients with high-grade PDUS signals ( $p=0.01,0.04,0.01$ respectively)

Table 1. Correlation coefficients between clinical, ultrasound and functional variables

\begin{tabular}{|c|c|c|c|c|c|c|}
\hline & \multicolumn{2}{|c|}{$\begin{array}{l}\text { BMOD synovitis } \\
\text { Total }\end{array}$} & \multicolumn{2}{|c|}{$\begin{array}{l}\text { BMOD erosions } \\
\text { Total }\end{array}$} & \multicolumn{2}{|c|}{$\begin{array}{l}\text { PDUS synovitis } \\
\text { Total }\end{array}$} \\
\hline & $r$ & $p$ & $r$ & $p$ & $r$ & $P$ \\
\hline DASH & 0.37 & $0.02^{*}$ & 0.19 & 0.20 & 0.13 & 0.38 \\
\hline HDI & 0.21 & 0.17 & 0.17 & 0.28 & 0.21 & 0.17 \\
\hline RAAD & 0.33 & $0.02^{*}$ & 0.41 & $0.00^{*}$ & 0.22 & 0.15 \\
\hline DAS 28 & -0.04 & 0.78 & 0.01 & 0.95 & -0.05 & 0.75 \\
\hline MS & 0.24 & 0.12 & -0.10 & 0.51 & 0.20 & 0.19 \\
\hline Disease duration & 0.13 & 0.38 & 0.46 & $0.00^{*}$ & -0.31 & $0.03^{*}$ \\
\hline Lateral GS & 0.07 & 0.64 & -0.06 & 0.69 & -0.06 & 0.70 \\
\hline Tip GS & 0.11 & 0.49 & -0.27 & 0.08 & 0.09 & 0.56 \\
\hline Three fingered GS & 0.21 & 0.89 & -0.17 & 0.27 & 0.05 & 0.76 \\
\hline Mass grasp & -0.08 & 0.59 & -0.078 & 0.61 & -0.12 & 0.43 \\
\hline
\end{tabular}

BMOD: B mode ultrasound, PDUS: Power Doppler ultrasound, DASH: Disabilities of the Arm, Shoulder and Hand, HDI: Hand disability index, RAAD: Rheumatoid Arthritis Articular Damage, DAS 28: Disease activity score, MS: Morning stiffness, GS: Grip strength. ${ }^{*} \mathrm{P}<0.05$.

Conclusions: US scores in established RA patients are usually high because of synovial hypertrophy. It is considered that the high grade PDUS signals are more appropriate for evaluation of long-standing RA patients. Furthermore in this study, grade 3 PDUS signals were found to be a good indicator of synovial inflammation, morning stiffness, and disability.

References:

[1] Concordance between Clinical and ultrasound findings in rheumatoid arthritis. Garrigues F, Jousse-Joulin S, Bouttier R et al. Joint Bone Spine 80 (2013) 597-603.

[2] Severity and Diurnal Improvement of Morning Stiffness Independently Associate with Tenosynovitis in Patients with Rheumatoid Arthritis. Kobayashi Y, Ikeda K, Nakamura T et al. Plos One (11) Doi: 10.1371/journal.pone.0166616. Disclosure of Interest: None declared

DOI: 10.1136/annrheumdis-2017-eular.2898

\section{AB0214 METHOTREXATE IN EARLY RHEUMATOID ARTHRITIS: A SINGLE-CENTER EVALUATION OF CLINICAL OUTCOME COMPARING TWO STARTING TREATMENT STRATEGIES}

F. Benaglio, S. Bugatti, G. Sakellariou, G. Crepaldi, G. Zanframundo, C. Montecucco, R. Caporali. Early Arthritis Clinic, Division of Rheumatology, University of Pavia, IRCCS Policlinico San Matteo Foundation, Pavia, Italy

Background: methotrexate (MTX) is considered the 'anchor drug' in the treatment of rheumatoid arthritis (RA) and it should be part of the first treatment strategy: there are many indications about the correct way to optimize the dosage, depending on clinical response and tolerability, but currently there is no shared evidence about the optimal starting dosage.

Objectives: to compare two different starting treatment strategies with MTX in patients with early RA evaluated at our Early Arthritis Clinic (EAC) in order to assess the rate of patients who reaches the target (remission/low disease activity) at 6 months, according with EULAR guidelines.

Methods: patients with RA (disease duration $<12$ months) evaluated at our EAC between 2005 and 2016 and treated with MTX parenterally and glucocorticoids (GC) were included. Patients followed a treat-to-target strategy to reach low disease activity with bimonthly tight control. Patients evaluated between 2005 and 2009 were initially treated with MTX $10 \mathrm{mg} /$ week + GC (group A) with increase of MTX to 15 and then $20 \mathrm{mg} /$ week in case of failure to reach the target; patients evaluated between 2010 and 2016 were initially treated with MTX 15 mg/week + GC (group B) with possible increase to 20 and $25 \mathrm{mg} /$ week. The DAS28 response was assessed after 6 months.

Results: 260 patients were analyzed: 123 in group A vs 137 in group B. At baseline patients showed differences in DAS28 $(5.2 \pm 1.15$ vs $4.6 \pm 1.16, p<0.0001)$ and $\mathrm{HAQ}(1,125$ vs 1 IQR IQR $0.75-1.8750 .375-1.5, \mathrm{p}=0.006)$; there were no differences in terms of autoimmunity. After 6 months of therapy there were no differences in clinical response: $32 \%$ of patients in the group $A$ reached the DAS28 remission vs $40 \%$ of the group B ( $p=n s), 27 \%$ in the group A reached the DAS28 low disease activity vs $24 \%$ of the group B $(p=n s), 41 \%$ of the group A was in moderate disease activity vs $36 \%$ in the group $B(p=n s)$. The need to increase the dosage of MTX during the first 6 months was similar: $27.6 \%$ of the group A vs $29.9 \%$ of the group B ( $p=n s)$, conversely, the need to reduce the dosage of MTX due to intolerance and/or adverse event was significantly higher in the group B (group A: $1.6 \%$ vs group B: $9.5 \%, p=0.014$ ).

Conclusions: the use of higher dose of MTX is associated with a higher rate of side effects but does not provide, at short term, a significant improvement in term of clinical outcome. Conversely, the initial use of MTX $10 \mathrm{mg} / \mathrm{week}$, with a quick dose titration in case of persistent disease activity, seems to be an appropriate option for many patients with early RA, as also recently suggested by the Utrecht Arthritis Cohort Study Group; in spite of this, there is an amount of patients who do not achieve the clinical target at short term regardless of the initial dose of MTX. Our experience suggests that in the early phase of RA treatment, in a context based on early diagnosis, tight control and treat to target, the clinical outcome seems to be linked more to the treatment strategy than to the drug dosage used. References:

[1] Combe B, et al. 2016 update of the EULAR recommendations for the management of early arthritis. Ann Rheum Dis-2016-210602.

[2] Nair SC, et al. Determining the lowest optimally effective methotrexate dose for Individual RA patients using their dose response relation in a tight control treatment approach. PLoS ONE 11:e0148791.

Disclosure of Interest: None declared

DOI: 10.1136/annrheumdis-2017-eular.6437

\section{AB0215 A LONGER MEAN SURVIVAL OF BIOLOGIC TREATMENTS IS ASSOCIATED WITH DAS28 REMISSION IN RHEUMATOID ARTHRITIS PATIENTS}

F. Ometto, C. Botsios, B. Raffeiner, D. Astorri, L. Friso, L. Bernardi, L. Punzi, A. Doria. Rheumatology Unit, Department of Medicine - Dimed, University of Padova, PADOVA, Italy

Objectives: To determine factors associated with remission (DAS28<2.6). We specifically considered the association of biologic treatment duration, number of biologic switches and survival of biologic treatment with remission.

Methods: We conducted a retrospective analysis on a monocentric cohort of rheumatoid arthritis patients. We included patients who were on biologic drugs at the time of the analysis (31st December 2016). We considered patients starting the first biologic treatment since January 2000 and with a follow-up $\geq 12$ months. We considered the following variables: demographics, positive rheumatoid factor (RF)/ anti-citrullinated peptides (ACPA), disease duration at the start of the first biologic treatment, number of biologic switches, clinical assessment at the last follow-up, concomitant DMARDs, prednisone dose, current biologic treatment. We also considered the mean survival of biologic treatments, defined as the duration of the biologic treatment of each patient divided by the number of biologics undergone by the patient.

Mann-Whitney test and chi-square test were used to assess the association of continuous and categorical variables with the outcome. Continuous measures are reported as medians and interquartile range. Multivariate regression analysis included all variables reaching a $p$ value $<0.2$ in univariate analysis

Results: We collected data of 330 patients. All patients had complete data. One hundred thirty-five patients $(40.9 \%)$ were in DAS28 remission. Characteristics of the patients are reported in Table I. We considered 609 biologic treatments (abatacept $n=61$; anti-TNF alpha $n=445$; anakinra $n=43$; tocilizumab $n=56$; rituximab $n=5$ ). Total biologic treatment duration in all patients was 9.62 years (5.68-12.53), in patients in remission 8.95 (4.70-12.53) and in patients not in remission $10.12(6.28-12.62)(p=0.248)$. Median number of previous biologic switches was $1.00(0-1.00)$ in patients in remission and not in remission ( $p=0.436)$. Survival of biologic treatments was 5.33 years $(2.89-7.72)$ in all patients, 4.57 (2.54-7.28) in patients in remission and 5.81 (3.49-7.93) in patients not in remission $(p=0.013)$.

All clinical assessments at the last follow-up were significantly associated with DAS28 remission. Mean prednisone dose was significantly lower in patients in DAS28 remission but was considered as a consequence of remission rather than a predictor (Table I). The type of current biologic treatment was not significantly associated with DAS28 remission.

Variables included in the multivariate regression analysis were: BMI, age, disease duration, positive RF/ACPA mean survival of each biologic treatment. All variables included in the model were independently associated with DAS28 remission. A higher BMI, older age, longer disease duration and positive RF/ACPA were negatively associated with remission. A longer mean survival of biologic

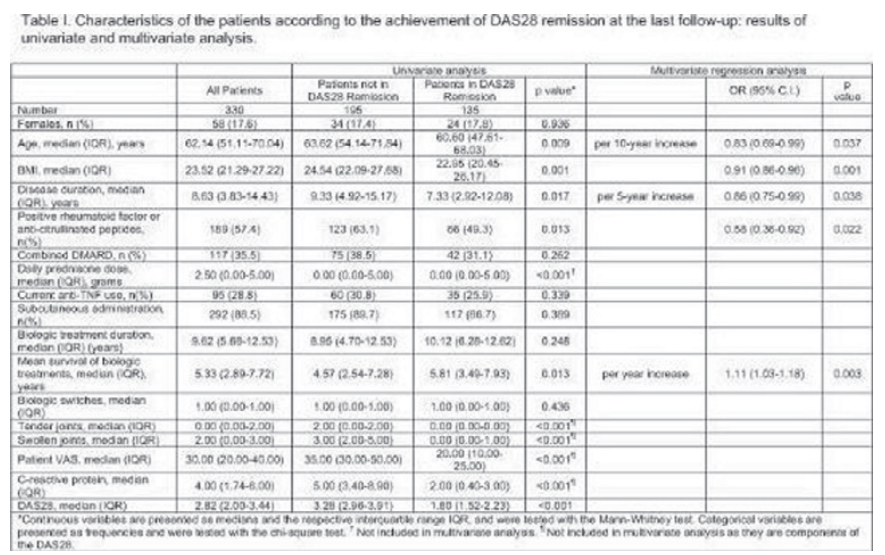

